\title{
Nano-hydroxyapatite/collagen film as a favorable substrate to maintain the phenotype and promote the growth of chondrocytes cultured in vitro
}

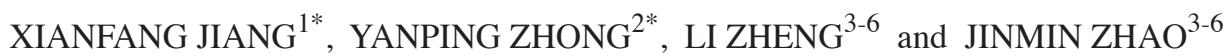 \\ ${ }^{1}$ The College of Stomatology; ${ }^{2}$ The Medical and Scientific Research Center; \\ ${ }^{3}$ Guangxi Engineering Center in Biomedical Material for Tissue and Organ Regeneration, The First Affiliated Hospital, \\ ${ }^{4}$ Department of Orthopaedics Trauma and Hand Surgery, The First Affiliated Hospital, ${ }^{5}$ Guangxi Collaborative Innovation Center \\ for Biomedicine, The First Affiliated Hospital, ${ }^{6}$ Guangxi Key Laboratory of Regenerative Medicine, The First Affiliated Hospital, \\ Guangxi Medical University, Nanning, Guangxi 530021, P.R. China
}

Received November 9, 2016; Accepted January 18, 2018

DOI: 10.3892/ijmm.2018.3431

\begin{abstract}
Autologous chondrocyte implantation (ACI) has emerged as a novel approach to cartilage repair through the use of harvested chondrocytes. However, the expansion of the chondrocytes from the donor tissue in vitro is restricted by the limited cell numbers and the dedifferentiation of the chondrocytes. The present study investigated the effect of collagen-based films, including collagen, hydroxyapatite (HA)/collagen (HC) and in situ synthesis of nano-HC (nHC), on monolayer cultures of chondrocytes. As a substrate for the chondrocytes monolayer culture in vitro, $\mathrm{nHC}$ was able to restrain the dedifferentiation of chondrocytes and facilitate cell expansion, which was detected by methyl

Correspondence to: Dr Li Zheng, Guangxi Engineering Center in Biomedical Material for Tissue and Organ Regeneration, The First Affiliated Hospital, Guangxi Medical University, 22 Shuangyong Road, Nanning, Guangxi 530021, P.R. China

E-mail: zhengli224@163.com

*Contributed equally
\end{abstract}

Abbreviations: ACI, autologous chondrocyte implantation; $\mathrm{AGC}$, aggrecan; calcein-AM, calcein-acetoxymethyl; $\mathrm{Ca}\left(\mathrm{NO}_{3}\right)_{2}$, calcium nitrate; Col I, type I collagen; Col II, type II collagen; DMEM, Dulbecco's modified Eagle's medium; DMMB, 1,9-dimethylmethylene blue; ECM, extracellular matrix; FBS, fetal bovine serum; GAGs, glycosaminoglycans; HA, hydroxyapatite; $\mathrm{HC}$, hydroxyapatite/collagen; H\&E, hematoxylin and eosin; IHC, immunohistochemistry; MTT, methyl thiazolyl tetrazolium; nHC, nano-hydroxyapatite/collagen; $\mathrm{NH}_{3} \cdot \mathrm{H}_{2} \mathrm{O}, \quad$ ammonium hydroxide; $\left(\mathrm{NH}_{4}\right)_{2} \mathrm{HPO}_{4} \cdot 12 \mathrm{H}_{2} \mathrm{O}$, diammonium phosphate; OD, optical density; PBS, phosphate-buffered solution; PI, propidium iodide; RT-qPCR, reverse transcription-quantitative polymerase chain reaction; SD, Sprague-Dawley; SEM, scanning electron microscope

Key words: chondrocytes, collagen, proliferation, differentiation, nano-hydroxyapatite thiazolyl tetrazolium assay, scanning electron microscopy, calcein-acetoxymethyl/propidium iodide staining, hematoxylin and eosin staining, Safranin O staining, immunohistochemical staining and reverse transcription-quantitative polymerase chain reaction. Furthermore, the $\mathrm{nHC}$ films significantly facilitated cell growth and enhanced the expression of cartilage-specific extracellular matrix (ECM) components, including aggrecan and type II collagen. In addition, $\mathrm{nHC}$ films markedly downregulated the expression of collagen type I, an indicator of dedifferentiation. The results indicated that $\mathrm{nHC}$, a collagen-based substrate optimized by nanoparticles, was able to better support cell growth and preserve cell phenotype compared with collagen alone or HC. The nHC film, which favors cell growth and prevents the dedifferentiation of chondrocytes, may therefore serve as a useful cartilage-like ECM for chondrocytes. In conclusion, $\mathrm{nHC}$ film is a promising substrate for the culture of chondrocytes in cell-based therapy.

\section{Introduction}

Articular cartilage has limited healing potential once injured. Autologous chondrocyte implantation (ACI) has emerged as a novel approach to cartilage repair through the use of harvested chondrocytes $(1,2)$. During the process of ACI, expansion of the chondrocytes from the donor tissue in vitro is indispensable (3). However, this approach is restricted by the limited cell numbers and the dedifferentiation of the chondrocytes when they are cultured in vitro. Dedifferentiated chondrocytes are characterized by a marked increase in collagen type I (Col I)and a decrease in cartilage-specific markers, including collagen type II (Col II) and aggrecan (AGC) (4).

Numerous pieces of evidence indicate that cell-cell and cell-extracellular matrix (ECM) directly influence cell signaling via cell adhesion molecules, including integrins and cadherins, which are crucial for cell functions (5-7). Scaffolds not only serve as templates for cells to facilitate cell motility, ECM synthesis and physiological storage of bioactive molecules (8), but also provide the advantage of guidance for cell differentiation by affecting cell-cell and cell-ECM 
interactions (9). Similar to the structure of hyaline cartilage, three-dimensional (3D) scaffolds, particularly the hydrogels, are highly recommended (10). It is generally accepted that the $3 \mathrm{D}$ environment favors the maintenance of the chondrocyte phenotype and supports redifferentiation of dedifferentiated articular chondrocytes (11-13). However, cells are encapsulated in matrix and cannot be harvested for further implantation. The difficulty of taking the cells out of the 3D matrices with their viability and functions intact therefore remains.

As an alternative, monolayer culture using an elaborate cellular microenvironment that is created mimicking the in vivo situation may assist in maintaining the cell phenotype and prevent dedifferentiation (14). Collagen is widely used for cartilage regeneration $(15,16)$, not only as it resembles the ECM of natural cartilage, but also as it has weak antigenicity, biodegradability and superior biocompatibility $(17,18)$. The collagen membranes have provided a monolayer culture system, which facilitated the expanding of chondrocyte cells (19), and have been used for autologous chondrocyte implantation (20,21). Without the addition of growth factors, mesenchymal stem cells cultured in collagen beads can differentiate into chondrocytes and form hyaline cartilage similar to native cartilage $(22,23)$. However, pure collagen has poor mechanical strength and less favorable bioactivity (24), which does not meet the criteria for cartilage tissue engineering. As cartilage is a weight-bearing tissue, the scaffold for cartilage engineering should be of an appropriate mechanical strength. Therefore, to improve the mechanical properties of collagen, the introduction of inorganic material is an optimal choice. Hydroxyapatite (HA) has been reported to reinforce the mechanical and biological properties of collagen $(25,26)$, and also showed potential for cartilage repair (27). In particular, nano-sized HA particles are superior to micrometric particles due to the higher surface/volume ratio, better dispersion and the possibility of mixing smaller amounts of HAs in the collagen matrix (28). Compared with mechanical or ultrasonic stirring, which always results in micro-HA, the in situ hybridization method enables the creation of nano-HA, with the advantage of obtaining a homogeneous biocomposite scaffold with well-distributed nano-HA particles (29). A previous study showed that collagen-HA by way of in situ hybridization can enhance the mechanical strength and facilitate chondrocyte growth (25). Thus, we hypothesize that nano-HA/collagen (nHC) film may be favorable cell substrate for in vitro culture of chondrocytes.

In the present study, nano-HA particles were synthesized innovatively in situ in collagen solution, forming nHC film. To verify its capacity in preventing chondrocytes from dedifferentiation in vitro, nHC film was used as a substrate for chondrocytes. Furthermore, chondrocyte proliferation on the novel gel films was compared with that of pure collagen and an HC film on which HA particles were prepared by physical mixing. The analysis of cell viability, morphology, phenotype, protein level and biological function were implemented. With the intention to preserve cell phenotype and promote cell growth to ensure sufficient and functional cells, this study may provide novel insights for cell-based therapy.

\section{Materials and methods}

Materials and chemicals. COLIA1 of calf origin and nano-HA powder were purchased from the Engineering Research
Center in Biomaterials, Sichuan University (Chengdu, Sichuan, China). Chemicals of analytical grade, including calcium nitrate $\left[\mathrm{Ca}\left(\mathrm{NO}_{3}\right)_{2}\right]$, ammonium hydroxide $\left(\mathrm{NH}_{3} \cdot \mathrm{H}_{2} \mathrm{O}\right)$, diammonium phosphate $\left[\left(\mathrm{NH}_{4}\right)_{2} \mathrm{HPO}_{4} \cdot 12 \mathrm{H}_{2} \mathrm{O}\right]$, glacial acetic acid, calcium chloride and sodium hydroxide were all purchased from Tianjin Kemiou Chemical Reagent Co., Ltd. (Tianjin, China). Type II collagenase, proteinase K solution, Hoechst 33258 and 1,9-dimethylmethylene blue (DMMB) were purchased from Sigma-Aldrich; Merck KGaA (Darmstadt, Germany). Dulbecco's modified Eagle's medium (DMEM) was obtained from GE Healthcare Life Sciences (Logan, UT, USA). Fetal bovine serum (FBS) was procured from Hangzhou Sijiqing Biological Engineering Materials Co., Ltd. (Hangzhou, China). Anti-COLIA1 and -COL1A2 antibodies and the immunohistochemistry (IHC) kit were purchased from Wuhan Boster Biological Technology, Ltd. (Wuhan, China). Phosphate-buffered saline (PBS) and trypsin was obtained from Beijing Solarbio Science and Technology Co., Ltd. (Beijing, China). A total of 20 healthy newborn Sprague-Dawley (SD) rats (age, 3-5 days; weight, 10-12 g; random gender) were obtained from the Experimental Animal Center of Guangxi Medical University (Nanning, China). The rats were housed in an SPF level lab under controlled a temperature of $20-24^{\circ} \mathrm{C}$ and a relative humidity of $50-60 \%$ with a $12 / 12 \mathrm{~h}$ light-dark cycle. All the rats had free access to formula food and water.

Preparation of $n H C$ hydrogel in situ. All the chemicals were stored at $4^{\circ} \mathrm{C}$ in sterile conditions (25). To prepare the nHC hydrogel, COLIA1 solution was neutralized by $1 \mathrm{~mol}$ glacial acetic acid and $1 \mathrm{~mol}$ sodium hydroxide, with a final concentration of $10 \mathrm{mg} / \mathrm{ml}$. Next, $1 \mathrm{~mol} / 1\left(\mathrm{NH}_{4}\right)_{2} \mathrm{HPO}_{4} \cdot 12 \mathrm{H}_{2} \mathrm{O}$ was added into the collagen solution. $\mathrm{Ca}\left(\mathrm{NO}_{3}\right)_{2}(1 \mathrm{~mol} / \mathrm{l})$ was used to adjust the ratio of $\mathrm{Ca} / \mathrm{P}$ to a ratio of 1.67 and then $\mathrm{NH}_{3} \cdot \mathrm{H}_{2} \mathrm{O}$ was titrated slowly to regulate the $\mathrm{pH}$ value up to 9 , with maintenance for $2 \mathrm{~h}$. The solution would be neutralized by $1 \mathrm{~mol}$ glacial acetic acid and $1 \mathrm{~mol}$ sodium hydroxide. Once the $\mathrm{pH}$ value was 7 , the solution would be gelatinized at $25^{\circ} \mathrm{C}$. The HC gel was fabricated by the physical mixing of nano-HA powders into collagen solution in a ratio of $10 \mathrm{mg}: 1 \mathrm{ml}$.

Isolation and culture of chondrocytes. This study was performed strictly according to the recommendations in the Guide for the Care and Use of Laboratory Animals of the National Institutes of Health. The protocol was approved by the Ethics Committee of Animal Experiments of Guangxi Medical University. All surgery was performed under sodium pentobarbital anesthesia, and all efforts were made to minimize suffering. Cartilage was isolated from newborn SD rats (3-5 days old) in sterile conditions. The new born SD rats were sacrificed by an intravenous injection of a euthanasia solution. Articular cartilage was isolated from the joints of the limbs in sterile conditions. Soft tissue attached to the surface of the cartilage was removed using $0.25 \mathrm{mg} / \mathrm{ml}$ trypsin at $37^{\circ} \mathrm{C}$ for $30 \mathrm{~min}$. The cartilage was then shred into $1 \mathrm{~mm}^{3}$ pieces with ophthalmic scissors. The tissue pieces were digested in $1 \mathrm{mg} / \mathrm{ml}$ type II collagenase for $3 \mathrm{~h}$. Finally, chondrocytes were collected and cultures on dishes in DMEM with $10 \%$ FBS. Subsequent to passaging 2 times, the cells were seeded at a density of $2.4 \times 10^{4} / \mathrm{cm}^{2}$ on dishes paved with $\mathrm{nHC}, \mathrm{HC}$ or COLIA1 gel. In the control 
group, chondrocytes were cultured in $10 \%$ FBS containing $10 \mathrm{ng} / \mathrm{ml}$ transforming growth factor- $\beta$ (TGF- $\beta$ ) (Peprotech, Inc., Rocky Hill, NJ, USA), 50 mg/ml insulin-transferring-selenium, $100 \mathrm{nmol} / 1$ dexamethasone and $50 \mu \mathrm{g} / \mathrm{ml}$ vitamin C (all Sigma-Aldrich; Merck KGaA). Experiments were performed at 2, 4 and 6 days of culture.

Proliferation of chondrocytes. The proliferation of the cells was observed by methyl thiazolyl tetrazolium (MTT) assay (Sigma-Aldrich; Merck KGaA). Briefly, chondrocytes $(5,000$ cells/well) were cultured in 96-well microplates coated with collagen, $\mathrm{HC}$ or $\mathrm{nHC}$ film for 1, 2, 3, 4, 5 and 6 days. MTT $(20 \mu \mathrm{l} ; 5 \mathrm{mg} / \mathrm{ml})$ was added into the culture medium $(200 \mu \mathrm{l})$ in each well. Following incubation for $4 \mathrm{~h}$ at $37^{\circ} \mathrm{C}$, the medium supernatant was removed carefully and dimethyl sulfoxide was added (150 $\mu \mathrm{l} /$ well). The optical density (OD) was detected by a microplate reader at $490 \mathrm{~nm}$.

Cells adhesion. A scanning electron microscope (SEM) was used to analyze the adhesion of the cells on the film surface. Slides coated with gel film seeded with chondrocytes were fixed in glutaraldehyde for $24 \mathrm{~h}$ at $4^{\circ} \mathrm{C}$. Following dehydration, drying and gold spraying in order, the film surfaces and cell-matrix interaction were studied with an SEM (Hitachi, Ltd., Tokyo, Japan) operating at $3 \mathrm{kV}$, and images were captured.

Cell viability examination. Chondrocyte viability on the gel film was measured utilizing a live-dead viability assay kit (Invitrogen; Thermo Fisher Scientific, Inc., Waltham, MA, USA). Subsequent to being washed in PBS, the chondrocytes were incubated in $1 \mathrm{ml}$ PBS containing $0.5 \mu \mathrm{l}$ calcein-acetoxymethyl (calcein-AM) and $2 \mu 1$ propidium iodide (PI) in the dark. After $5 \mathrm{~min}$, the viability of the cells was visualized with a laser scanning confocal microscope (NIS Elements, version 2.1, Nikon A1; Nikon, Tokyo, Japan) and images were captured.

Morphological analysis. Subsequent to being cultured for 2, 4 or 6 days, the chondrocytes were fixed in $4 \%(\mathrm{w} / \mathrm{v})$ paraformaldehyde (Beijing Solarbio Science and Technology Co., Ltd.) for $30 \mathrm{~min}$. Hematoxylin and eosin (H\&E; Beyotime, Shanghai, China) was used to dye the nuclei and cytoplasm, respectively, at room temperature for $5 \mathrm{~min}$. Finally, samples were gradually dehydrated in $75 \%$ alcohol (10 sec), $95 \%$ alcohol (10 sec), anhydrousalcohol (10 sec) (Yong Da, Tianjing, China) successively at room temperature. They were them dried in a drying oven (DHG-9140; Jing Hong, Shanghai, China) at $60^{\circ} \mathrm{C}$ for $30 \mathrm{sec}$, and sealed with neutral gum (Beijing Solarbio Science and Technology Co., Ltd.) and observed using a microscope (BX46; Olympus, Tokyo, Japan).

Aggrecan secretion. Safranin O staining solution was used to detect the AGC secretion of the chondrocytes seeded on gel film. Subsequent to fixing and washing, the cells were incubated with Safranin O (Beijing Solarbio Science and Technology Co., Ltd.) at room temperature for $20 \mathrm{~min}$. Next, the samples were gradually dehydrated, sealed with neutral gum and observed. To further detect the AGC secretion ability of the chondrocytes, the cells were digested with proteinase $\mathrm{K}$ solution for $16 \mathrm{~h}$ at $60^{\circ} \mathrm{C}$. The DNA production was measured by spectrofluorometer using Hoechst 33258 dye at room temperature for $5 \mathrm{~min}$ in the dark. The glycosaminoglycan (GAG) content was quantified by DMMB assay. GAG production in each cell was normalized to the total DNA content of the cells.

Immunohistochemical staining. To analyze the cartilage-like matrix production of chondrocytes, COLIA1 and COL1A2 were detected by IHC using monoclonal antibodies to the proteins of interest. The cells were fixed in $4 \%(\mathrm{w} / \mathrm{v})$ paraformaldehyde (Beijing Solarbio Science and Technology Co., Ltd.) at room temperature for $30 \mathrm{~min}$ and then treated with $0.01 \%$ Triton X-100 (Beyotime) for 10 min, and then $\mathrm{H}_{2} \mathrm{O}_{2}(3 \%$; Beyotime) was added to eliminate endogenous peroxidase activity for $10 \mathrm{~min}$. Goat serum (5\%; Wuhan Boster Biological Technology, Ltd.) was used to block the non-specific binding sites at room temperature for $15 \mathrm{~min}$. After $10 \mathrm{~min}$, the samples were incubated with primary antibodies against COLIA1 (1:100; BA0325; Wuhan Boster Biological Technology, Ltd.) and COL1A2 (1:100; BA0533; Wuhan Boster Biological Technology, Ltd.) at $4^{\circ} \mathrm{C}$ overnight. Subsequent to rewarming at room temperature for $30 \mathrm{~min}$, the cells were incubated with the secondary antibody (1:100; BA1005; Wuhan Boster Biological Technology, Ltd.) for $10 \mathrm{~min}$. A 3,3'-diaminobenzidine tetrahydrochloride kit (Wuhan Boster Biological Technology, Ltd.) was used to visualize the antibody binding at room temperature for $2 \mathrm{~min}$. Hematoxylin was used to dye the nuclei at room temperature for $15 \mathrm{sec}$. Finally, samples were gradually dehydrated in 75\% alcohol (10 sec), 95\% alcohol (10 sec) , anhydrousalcohol (10 sec) (Yong Da) successively at room temperature. After being dried in drying oven (DHG-9140; Jing Hong) at $60^{\circ} \mathrm{C}$ for $30 \mathrm{sec}$, the samples were sealed with neutral gum (Beijing Solarbio Science and Technology Co., Ltd.) and observed using a microscope (BX46; Olympus).

Reverse transcription-quantitative polymerase chain reaction (RT-qPCR) analysis. Total RNA was isolated from the cell/hydrogel constructs using an extraction kit (Tiangen Biotech Co., Ltd., Beijing, China) at 6 days of culture. RNA was reverse transcribed by First Strand cDNA Synthesis kit (Roche Diagnostics, Basel, Switzerland) according to the manufacturer's protocols. The cDNAs were then subjected to RT-PCR to measure the expression of COLIA1 and COL1A2, and AGC. Briefly, according to the RT-PCR kit (containing SYBR-Green I) protocol (Roche Diagnostics $\mathrm{GmbH}$, Mannheim, Germany), $1 \mu 1$ RNA, 30 pmol forward and reverse primers (Liuhe Genomics Technology Co., Peiking, China) and other reagents in the kit were added into the reaction tube. The initial denaturation stage was at $95^{\circ} \mathrm{C}$ for $5 \mathrm{~min}$, followed by 35 cycles of PCR. Each cycle occurred at $94^{\circ} \mathrm{C}$ for $40 \mathrm{sec}$, $56^{\circ} \mathrm{C}$ (AGC) or $57^{\circ} \mathrm{C}$ ( $\beta$-actin, COLIA1 and COL1A2) for $40 \mathrm{sec}$, and $72^{\circ} \mathrm{C}$ for $90 \mathrm{sec}$. Finally, extension occurred at $72^{\circ} \mathrm{C}$ for $5 \mathrm{~min}$. Relative quantification was calculated using the $2^{-\Delta \Delta \mathrm{Cq}}$ method (30) and all the results were normalized to a house-keeping gene, $\beta$-actin. The sequence of primers for $\beta$-actin, AGC, COLIA1 and COL1A2 were as follows: $\beta$-actin forward, 5'-ATGATATCGCCGCGCTCGTCGT-3' and reverse, 5'-CCTCGTCGCCCACATAGGAATC-3'; AGC forward, 5'-GAGTGGGCGGTGAGGAGGACAT-3' and reverse, 5'-CTGCGGCGCCGTGGGGGAGA-3'; COLIA1 


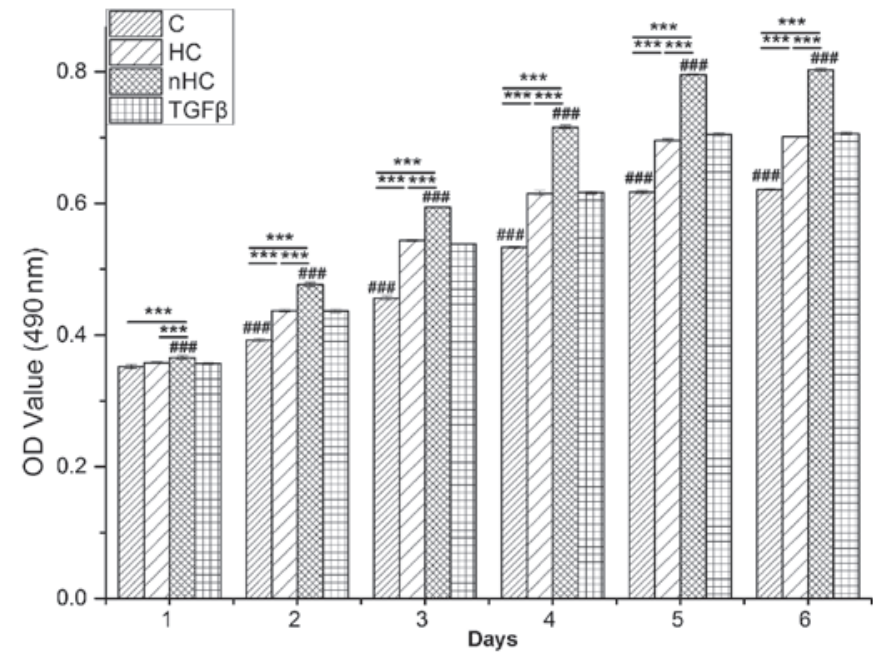

Figure 1. Proliferation of chondrocytes. Chondrocytes were seeded on the gel film at a density of 5,000 cells/well in 96-well microplates. Cytoviability of the chondrocytes on the gel film was measured by MTT assay every day. The data are reported as the mean \pm standard deviation. ${ }^{*} \mathrm{P}<0.05$, ${ }^{* *} \mathrm{P}<0.01$ and ${ }^{* * *} \mathrm{P}<0.001$ vs. the collagen-based groups; ${ }^{\#} \mathrm{P}<0.05,{ }^{\# \#} \mathrm{P}<0.01$ and ${ }^{\# \# \#} \mathrm{P}<0.001$ for comparisons between the collagen-based groups and the TGF- $\beta$ group. OD, optical density; TGF- $\beta$, transforming growth factor- $\beta$; , collagen; HC, hydroxyapatite/collagen; $\mathrm{nHC}$, nano-HC.

forward, 5'-CGGCGGTGGTTACGACTTTGGTT-3' and reverse, 5'-GGGTTCTTCCGGGAGCCTTCAG-3'; and COL1A2 forward, 5'-GCCACCGTGCCCAAGAAGAACT-3' and reverse, 5'-ACAGCAGGCGCAGGAAGCTCAT-3'.

Statistical analysis. Every experiment was conducted at least three times for the different days, and samples were collected in triplicate for each group. The statistical differences were measured by a one-way analysis of variance. Firstly, homogeneity of variances was calculated by Levene's test $(\alpha=0.05)$. Secondly, there was significant difference between each group if $\mathrm{F}>\mathrm{F} \alpha(\alpha=0.05), \mathrm{P}<0.05$. Finally, multiple comparisons were conducted using the Student-Newman-Keuls post hoc test.

\section{Results}

Chondrocyte proliferation. Proliferation of chondrocytes cultured on the gel film was detected by MTT. The results showed that cells proliferated in a time-dependent manner (Fig.1). In the early culture period, cells proliferated rapidly and then reached a plateau at 4 days. Comparatively, the OD value of the nHC group was the highest followed by that of the TGF- $\beta$ group, the $\mathrm{HC}$ group and the collagen group $(\mathrm{P}<0.05)$, which indicates that $\mathrm{nHC}$ gel supports cell growth the most markedly. There was no significant difference in OD value between the TGF- $\beta$ group and the HC group.

Chondrocyte distribution. The chondrocyte distribution on the gel films was observed under a SEM (Fig. 2). The number of cells adhered to the $\mathrm{nHC}$ film was much higher than that adhered to the others, suggesting that the $\mathrm{nHC}$ film could better support cell growth.

Cells viability. The chondrocyte viability was examined by calcein-AM/PI staining (Fig. 3) with alive cells depicted in green and dead cells in red (Fig. 3A). The number of the cells in green or red was calculated by Image-Pro Plus 6.0 (National Institutes of Health, Bethesda, USA) respectively after importing the pictures. The results showed that cells survival (Fig. 3B) on the $\mathrm{nHC}$ film was much higher than that in the TGF- $\beta$ group and on HC and collagen film, which was consistent with the results of the MTT assay. Furthermore, the viable to dead ratio (Fig. 3B) of the cells cultured on $\mathrm{nHC}$ film was higher than that of the control groups, indicating that the nHC film may serve as a substrate of benefit for chondrocyte survival and proliferation.

General observation. Chondrocytes seeded on the gel film were measured by H\&E staining (Fig. 4). A greater number of cell clusters formed by aggregation of chondrocytes were observed in the nHC group.

Aggrecan secretion. To determinate the AGC secretion of chondrocytes seeded on the film, samples were stained with Safranin O. The AGC appeared orange following reaction with Safranin O. The results of the Safranin O staining (Fig. 5A) showed that the orange color was much more evident in the $\mathrm{nHC}$ group than in the $\mathrm{HC}$ and collagen groups. The histograms in Fig. 5B show that the GAG and DNA contents were highest in the $\mathrm{nHC}$ group compared with that in the other collagen-based groups and even the positive group, which was TGF- $\beta$ added to the culture medium. However, the ratio of GAG to DNA in the nHC group was lower than that of the TGF- $\beta$ group, which indicated that nHC film could serve as an optimal substrate for chondrocyte growth, but that it could not maintain the phenotype equal to using TGF- $\beta$.

Immunohistochemical staining. Immunohistochemical staining was used to detect the indicators of cartilage ECM, COLIA1 or COL1A2 (Fig. 6). The expression of COL1A2 was stronger and that of COLIA1 was weaker in the $\mathrm{nHC}$ group compared with that in the $\mathrm{HC}$ and pure collagen groups, indicating that the chondrocyte phenotype and biological functions could be maintained effectively when cells were cultured on $\mathrm{nHC}$ film for a long period of time.

$R T-q P C R$ analysis. RT-qPCR analysis of tissues cultured for 6 days in vitro showed that there was a significant difference in the gene expression of AGC, COLIA1 or COL1A2 among the collagen-based hydrogels $(\mathrm{P}<0.05)$ (Fig. 7). COL1A2 exhibited higher mRNA expression and COL-I exhibited expression in the $\mathrm{nHC}$ group compared with the control groups, indicating that the ratio of COL1A2 to COLIA1 was enhanced. Therefore, as a culture matrix, nHC gel may increase the synthesis of cartilage marker and it is reasonable to speculate that the chondrocyte phenotype with no dedifferentiation was maintained in $\mathrm{nHC}$ film.

\section{Discussion}

The present study focused on the biomimetic monolayer as a substrate for the in vitro culture of chondrocytes to preserve phenotype and promote cell growth, in order to provide a promising cell reservoir in cell-based therapy. Based on 

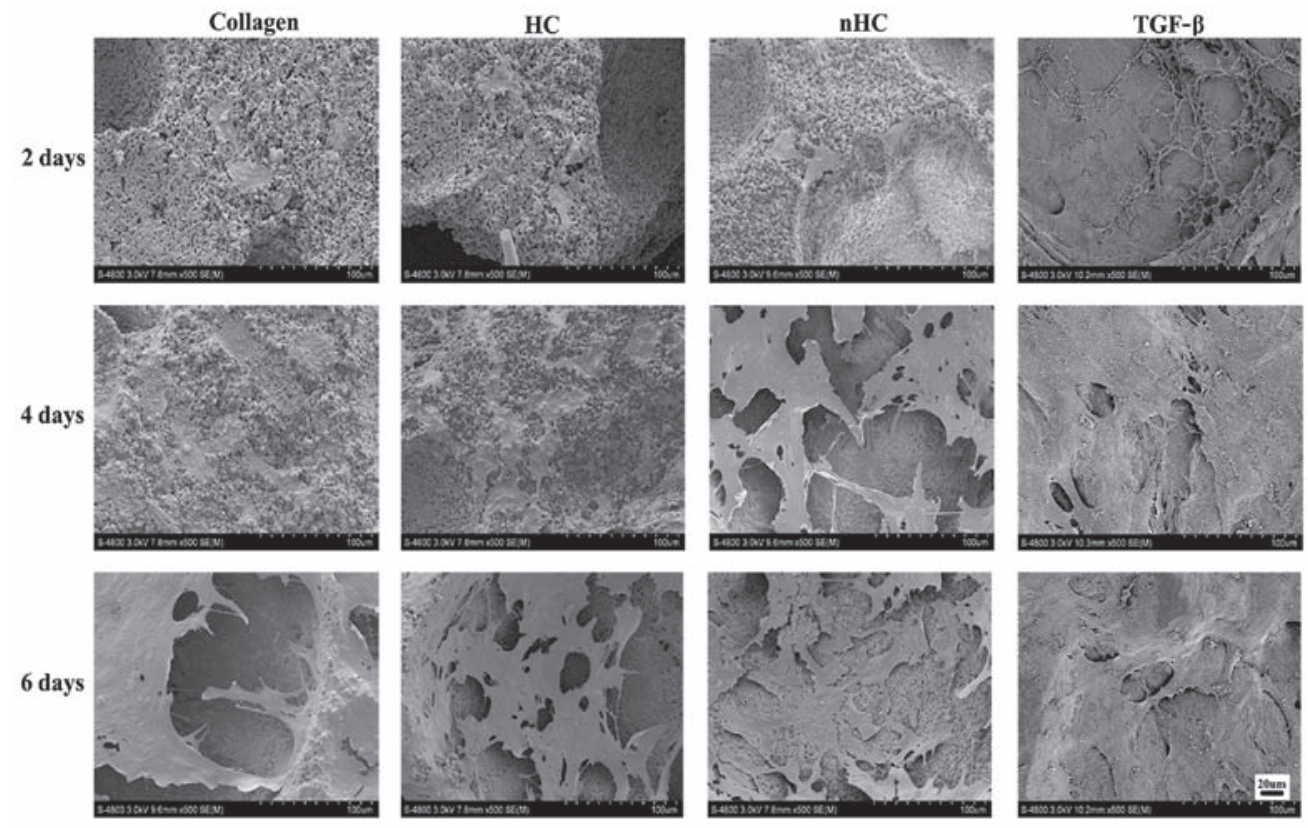

Figure 2. Chondrocyte distribution. The chondrocyte distribution on the gel films was observed by scanning electron microscope. The number of cells adhered to the $\mathrm{nHC}$ film was much higher than that adhered to the others, suggesting that the $\mathrm{nHC}$ film could better support cell growth. TGF- $\beta$, transforming growth factor- $\beta$; HC, hydroxyapatite/collagen; $\mathrm{nHC}$, nano-HC.
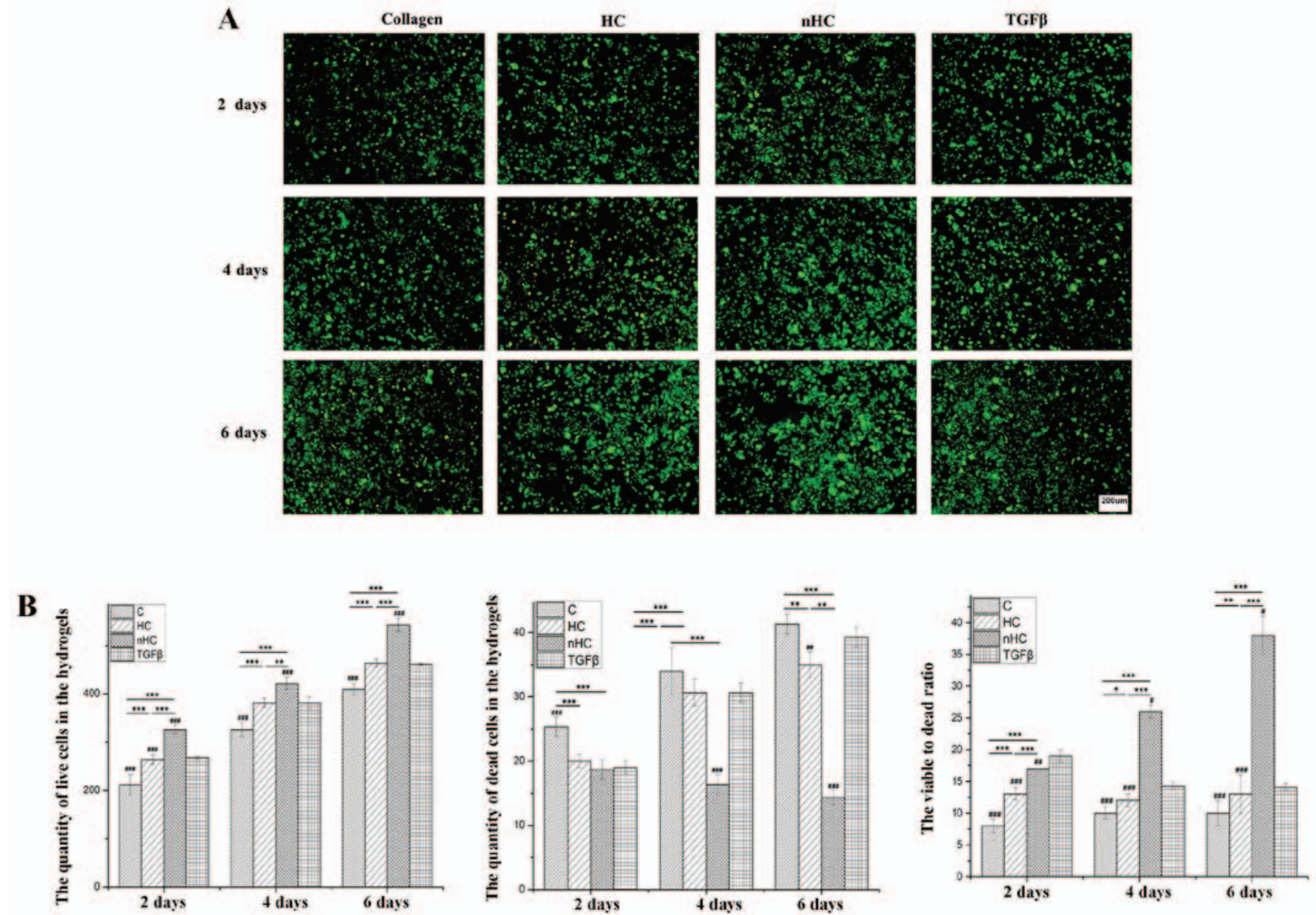

Figure 3. Cell viability. (A) Cell viability was examined by calcein-AM/PI staining. Cells seeded on nHC, HC and pure collagen film are shown. Cells in green are alive and cells in red are dead. (B) The quantities of live and dead cells were calculated and analyzed from the results of the calcein-AM/PI staining images. The cell numbers were counted using the 'cell calculating' toolbar in Nikon A1 software. The data are reported as the mean \pm standard deviation. " $\mathrm{P}<0.05$, ${ }^{* *} \mathrm{P}<0.01$ and ${ }^{* * *} \mathrm{P}<0.001$ vs. the collagen-based groups; ${ }^{*} \mathrm{P}<0.05,{ }^{\# \#} \mathrm{P}<0.01$ and ${ }^{\# \# t} \mathrm{P}<0.001$ for comparisons between the collagen-based groups and the TGF- $\beta$ group. TGF- $\beta$, transforming growth factor- $\beta$; C, collagen; HC, hydroxyapatite/collagen; nHC, nano-HC; calcein-AM/PI, acetoxymethyl/propidium iodide. 

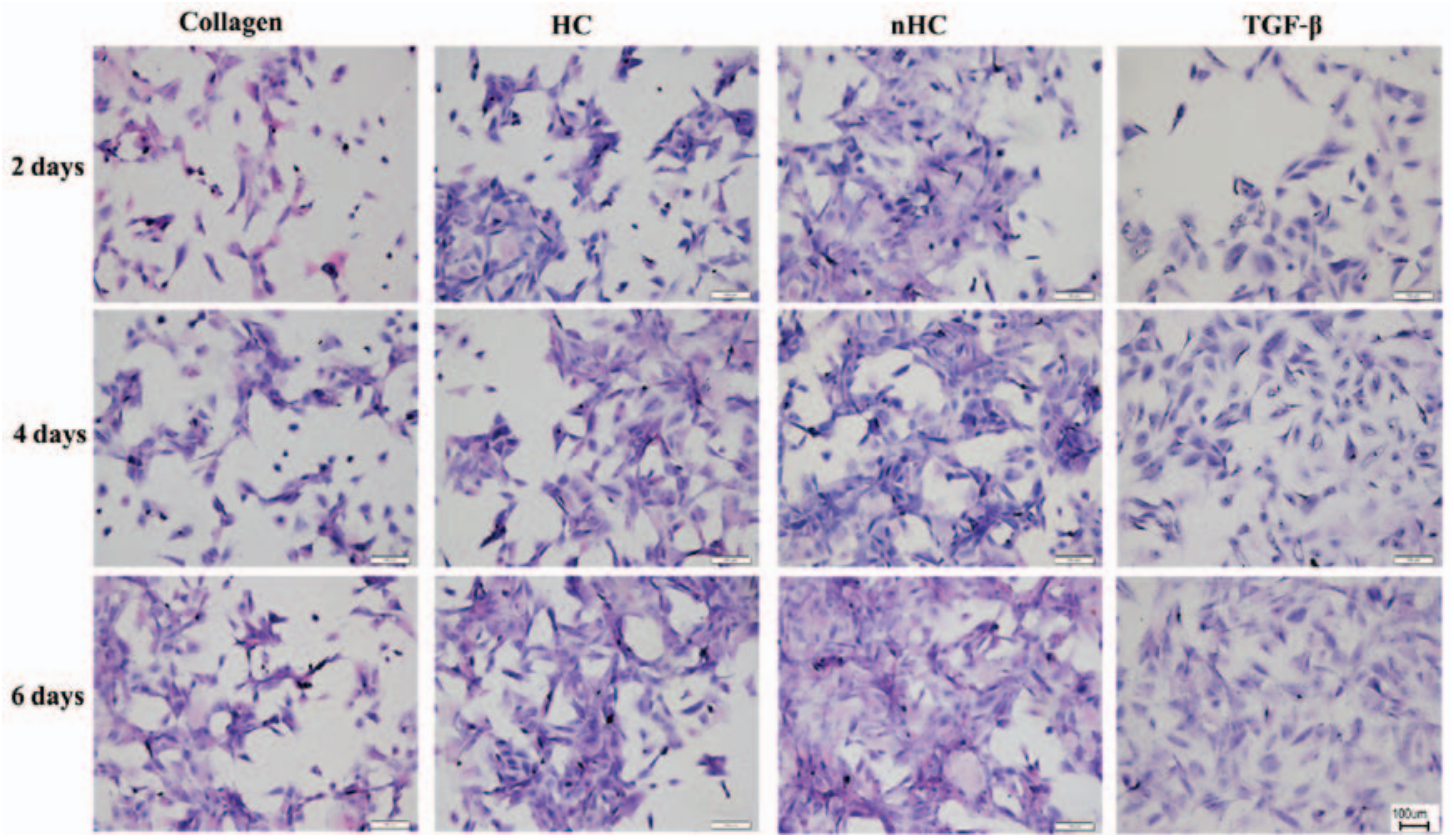

Figure 4. General observation. Chondrocytes seeded on the gel film were measured by hematoxylin and eosin staining. A greater number of cell clusters formed by the aggregation of chondrocytes was observed in the $\mathrm{nHC}$ group than the other groups. HC, hydroxyapatite/collagen; nHC, nano-HC; calcein-AM/PI, acetoxymethyl/propidium iodide; TGF- $\beta$, transforming growth factor- $\beta$.

A

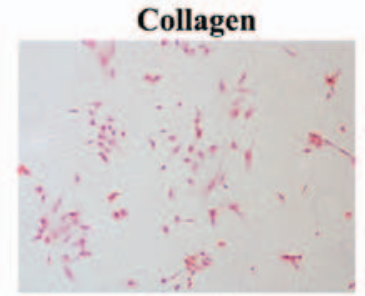

2 days

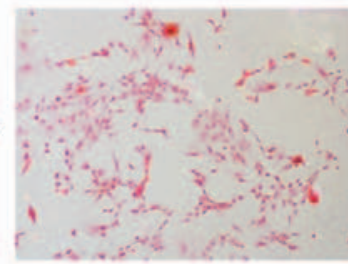

4 days

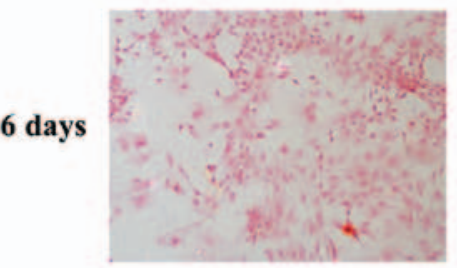

HC
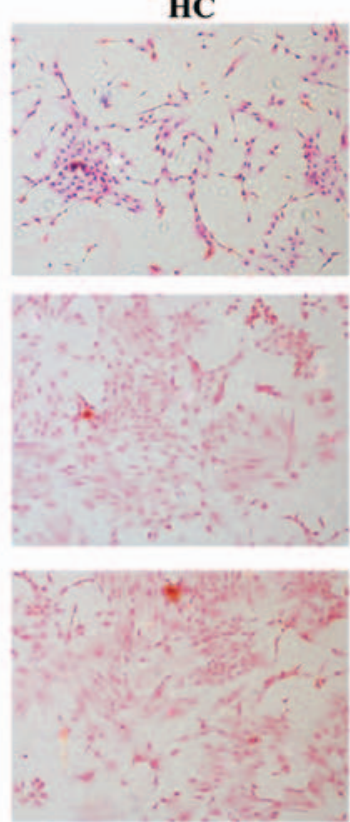

B
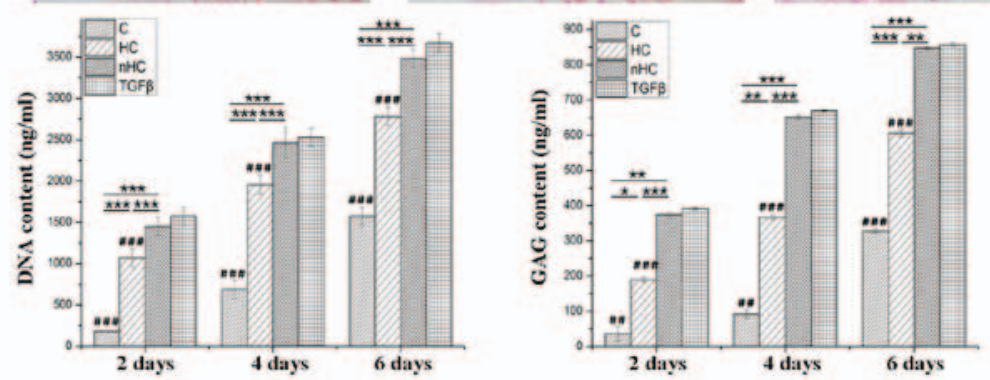

nHC
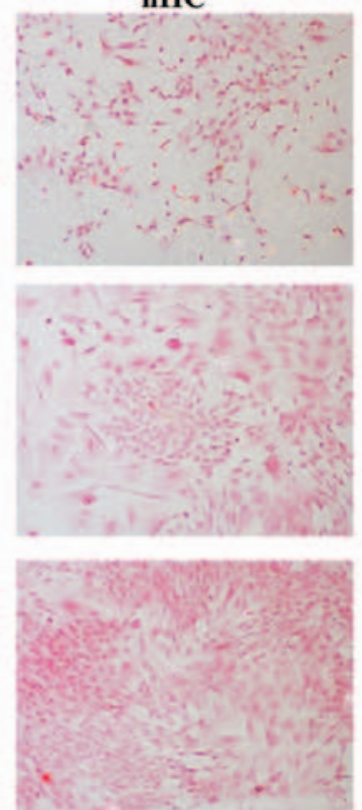

TGFB
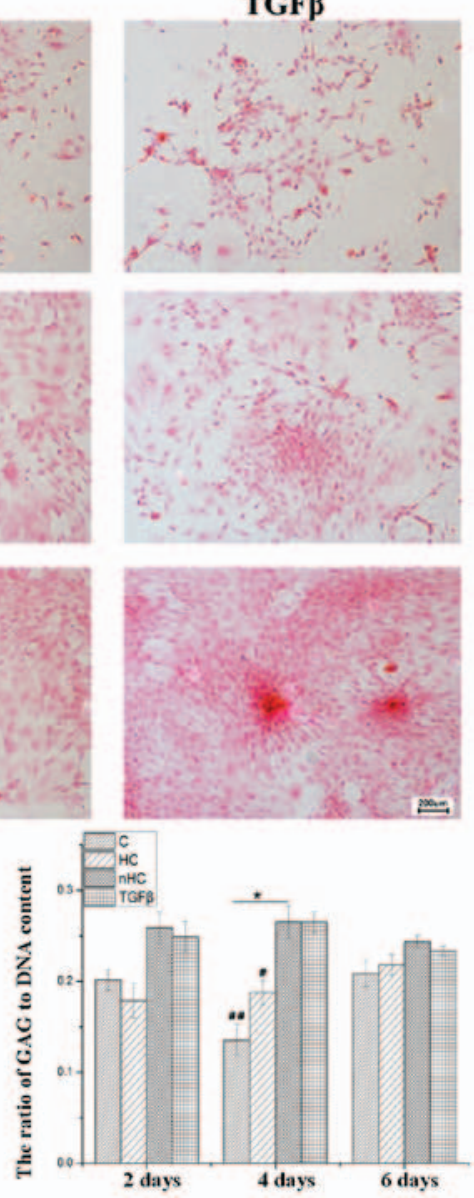

Figure 5. Aggrecan secretion. (A) AGC appeared orange following reaction with safranin $\mathrm{O}$. The results of the safranin $\mathrm{O}$ staining show that the orange color is more evident in the $\mathrm{nHC}$ group than in the $\mathrm{HC}$ and collagen groups. (B) The histograms show that the GAGs and DNA contents were highest in the nHC group than in the other collagen-based groups and even the positive group, which was TGF- $\beta$ added to culture medium. However, the ratio of GAG to DNA in the nHC group was lower than in the TGF- $\beta$ group. The data are reported as the mean \pm standard deviation. ${ }^{*} \mathrm{P}<0.05,{ }^{* * *} \mathrm{P}<0.01$ and ${ }^{* * * *} \mathrm{P}<0.001$ vs. the collagen-based groups; ${ }^{\#} \mathrm{P}<0.05,{ }^{\# \#} \mathrm{P}<0.01$ and ${ }^{\# \# \#} \mathrm{P}<0.001$ for comparisons between the collagen-based groups and the TGF- $\beta$ group. TGF- $\beta$, transforming growth factor- $\beta$; C, collagen; HC, hydroxyapatite/collagen; nHC, nano-HC; calcein-AM/PI, acetoxymethyl/propidium iodide; GAGs, glycosaminoglycans. 


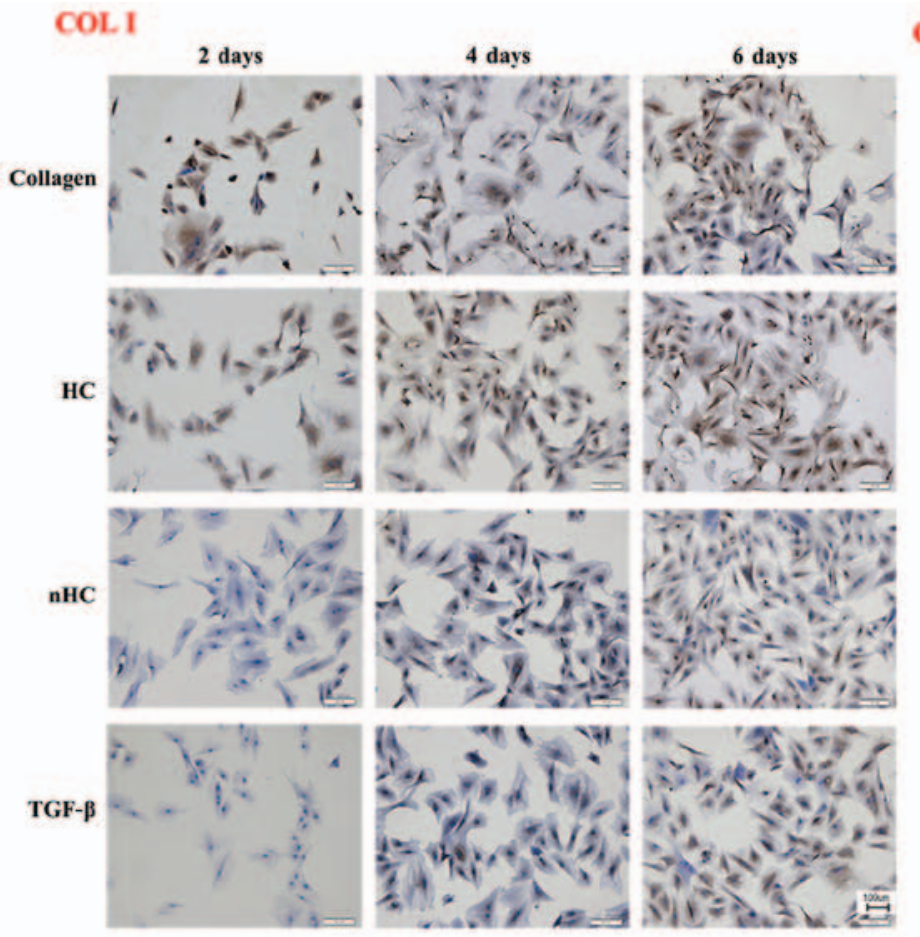

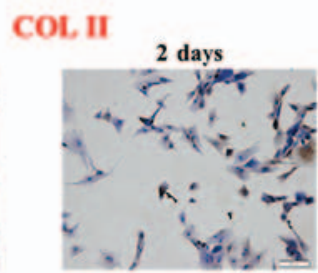
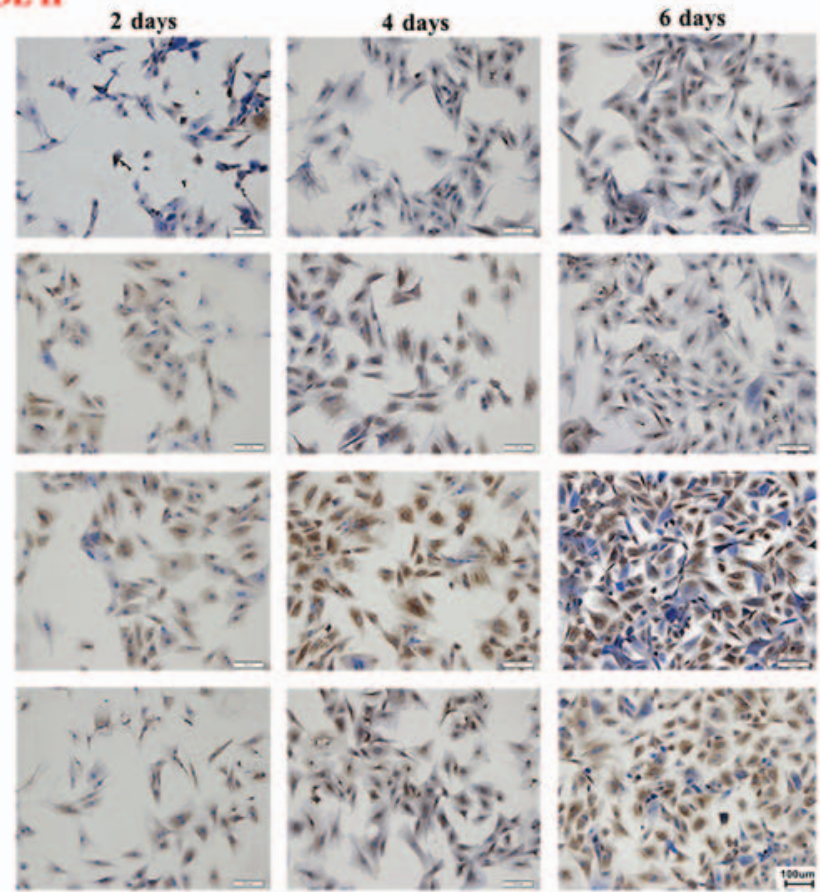

Figure 6. Immunohistochemical staining. Stronger positive expression (brown-yellow color) of Col II and weaker expression of Col I was observed in the nHC group compared with that in the $\mathrm{HC}$ and pure collagen groups, indicating that the chondrcocyte phenotype and biological functions could be maintained effectively when cells were cultured on $\mathrm{nHC}$ film for a long time period. HC, hydroxyapatite/collagen; nHC, nano-HC; calcein-AM/PI, acetoxymethyl/propidium iodide; TGF- $\beta$, transforming growth factor- $\beta$; COL-I, collagen type I; COL-II, collagen type II.

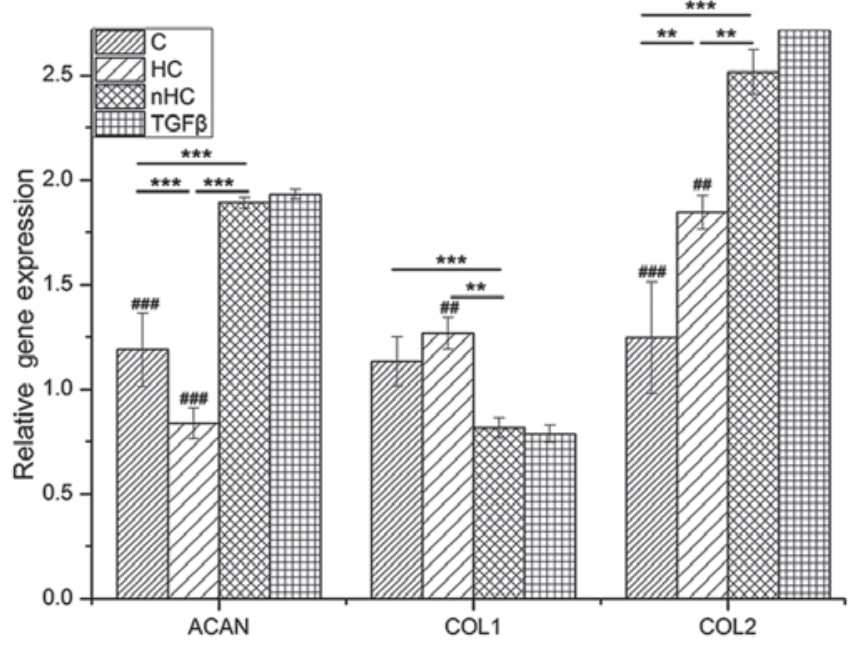

Figure 7. RT-qPCR analysis. Cartilage matrix relative gene expression was analyzed by RT-qPCR. The chondrocytes were seeded on the $\mathrm{nHC}, \mathrm{HC}$ and pure collagen films and cultured for 6 days. Gene expression in cells relative to the control group was calculated by the $2^{-\Delta \Delta \mathrm{Cq}}$ method using the $\beta$-actin gene as the internal control. The data are reported as the mean \pm standard deviation. ${ }^{*} \mathrm{P}<0.05,{ }^{* *} \mathrm{P}<0.01$ and ${ }^{* * * *} \mathrm{P}<0.001$ vs. the collagen-based groups; ${ }^{\#} \mathrm{P}<0.05,{ }^{\# \#} \mathrm{P}<0.01$ and ${ }^{\# \# \#} \mathrm{P}<0.001$ for comparisons between the collagen-based groups and the TGF- $\beta$ group. HC, hydroxyapatite/collagen; $\mathrm{nHC}$, nano-HC; calcein-AM/PI, acetoxymethyl/propidium iodide; TGF- $\beta$, transforming growth factor- $\beta$; COL-I, collagen type I; COL-II, collagen type II; RT-qPCR, reverse transcription-quantitative polymerase chain reaction.

our previous findings, we chose $\mathrm{nHC}$ film by way of in situ synthesis and compared with collagen and mixed HC films.

In the present study, the results showed that collagen, $\mathrm{HC}$ and $\mathrm{nHC}$ films could support the growth of chondrocytes, as demonstrated by cell proliferation assays, morphological examinations and cell viability analyses. Compared with the other collagen-based groups, $\mathrm{nHC}$ film showed superiority with regard to growth promotion and phenotype maintenance for chondrocytes. It is well known that chondrocytes are anchorage-dependent and require attachment to the ECM in order to survive and proliferate (31). Collagen provides a more native surface for chondrocytes, as it is the major component of cartilage ECM. Most importantly, collagen possesses ligands that favor cellular attachment. It was previously reported that collagen membranes seeded with chondrocytes appeared to improve cartilage healing by improving composite histological scores, cartilage GAG and DNA contents, and mechanical properties in vivo (32). In vitro, chondrocytes treated with collagen in 2D monolayer culture maintained high expression of characteristic chondrocyte markers, whereas the expression of the fibrocartilage marker was minimal (33). Furthermore, in the present study, expression of cartilage-specific genes and proteins, including COL1A2 and AGC, was enhanced with the increase in cell proliferation and growth, as demonstrated by MTT, RT-qPCR and immunohistology. This indicates that collagen-based substrates facilitate the maintenance of a differentiated phenotype for chondrocytes. Thus, collagen-based films are preferable as cell substrates for chondrocyte culture in vitro.

Further, the addition of HA particles, whether micro- or nano-scale, were found to enhance cell attachment more markedly than collagen alone. These results corroborate previous studies showing that $\mathrm{HC}$ composites are preferable over collagen in that HA strengthens the bioactivity of collagen (25). When combining collagen and HA, the wettability and permeability of the composite could be improved, resulting into culture medium penetration that 
is favorable for cell growth (34). The HA particles are spread on the film very evenly and this is expected to increase the chances for cells to make contact with HA particles, which may enhance cell-ECM interactions (35). Comparatively, $\mathrm{nHC}$ by way of in situ synthesis is superior to the conventional blend-mixing HC composites. Without the aggregation of nano-HA, nano-sized HA synthesized in situ can provide a higher surface area for cell growth, which may increase cellular proliferation $(36,37)$. Unlike ultrasonic or mechanical mixing, the in situ hybridization technique $(29,38)$ ensures the crystallization of nano-HA (39), with the advantage of obtaining a homogeneous hybrid scaffold with uniformly distributed nano-HA particles $(25,40)$. Our previous study showed that nano-HA particles synthesized in situ were bestowed with enhanced mechanical properties and improved the biological activity of the 3D scaffold (25). In the present study, the nHC film encouraged cell proliferation and prevented chondrocyte dedifferentiation, suggesting its role as a favorable substrate for chondrocytes.

In conclusion, the present study investigated the effect of collagen-based substrate on the growth and phenotype maintenance of chondrocytes when expanded in vitro. As evidenced by MTT assay, use of an SEM, calcein-AM/PI staining, H\&E staining, Safranin O staining, IHC and RT-qPCR, cell growth and cartilage-specific ECM components, including AGC and COL1A2, were promoted in the $\mathrm{nHC}$ film compared with that in the control. Expression of COLIA1, an indicator of dedifferentiation, was downregulated in the collagen-based film groups. $\mathrm{nHC}$ showed the best performance among all the collagen-based groups. The nHC film may serve as a cartilage-like ECM, and favors cell growth and prevention of dedifferentiation. Taken together, these results show that $\mathrm{nHC}$ composite film is a promising substrate for the culture of chondrocytes for cell-based therapy.

\section{Acknowledgements}

The authors thank Zhenhui Lu and Qin Liu for kindly offering technical guidance for IHC staining.

\section{Funding}

This study was financially supported by the National Science and Technology Pillar Program of China (grant no. 2012BAI42G00), the National Key Research and Development Program of China (2016YFB0700804), the National Natural Science Fund of China (grant no. 81472054), the Scientific and Technical Research Project in Guangxi Universities (KY2015LX059), High Level Innovation Teams and Outstanding Scholars in Guangxi Universities (the third batch) and the Key Scientific Research Collaboration Program of Guangxi Biomedical Collaborative Innovation Center (GCICB-SR-2017002).

\section{Availability of data and materials}

All data generated or analyzed during this study are included in this published article.

\section{Authors' contributions}

Xianfang Jiang and Yanping Zhong contributed equally to this study. Li Zheng designed the study. Xianfang Jiang conducted the study. Yanping Zhong conducted the data analysis. Jinmin Zhao revised the manuscript. All authors contributed to discussion of the results and approved the final version.

\section{Ethics approval and consent to participate}

This study was carried out strictly according to the recommendations in the Guide for the Care and Use of Laboratory Animals of the National Institutes of Health. The protocol was approved by the Ethics Committee of Animal Experiments of Guangxi Medical University.

\section{Consent for publication}

Not applicable

\section{Competing interests}

The authors declare that they have no competing interests.

\section{References}

1. Brittberg M, Lindahl A, Nilsson A, Ohlsson C, Isaksson O and Peterson L: Treatment of deep cartilage defects in the knee with autologous chondrocyte transplantation. N Engl J Med 331: 889-895, 1994.

2. Chung $\mathrm{C}$ and Burdick JA: Engineering cartilage tissue. Adv Drug Deliv Rev 60: 243-262, 2008.

3. Lee JI, Sato M, Kim HW and Mochida J: Transplantatation of scaffold-free spheroids composed of synovium-derived cells and chondrocytes for the treatment of cartilage defects of the knee. Eur Cell Mater 22: 275-290, 2011.

4. Vinatier C, Gauthier O, Fatimi A, Merceron C, Masson M, Moreau A, Moreau F, Fellah B, Weiss P and Guicheux J: An injectable cellulose-based hydrogel for the transfer of autologous nasal chondrocytes in articular cartilage defects. Biotechnol Bioeng 102: 1259-1267, 2009.

5. Knudson W and Loeser RF: CD44 and integrin matrix receptors participate in cartilage homeostasis. Cell Mol Life Sci 59: 36-44, 2002.

6. Weber GF, Bjerke MA and DeSimone DW: Integrins and cadherins join forces to form adhesive networks. J Cell Sci 124: 1183-1193, 2011.

7. Chen X and Gumbiner BM: Crosstalk between different adhesion molecules. Curr Opin Cell Biol 18: 572-578, 2006.

8. Risbud MV and Sittinger M: Tissue engineering: advances in in vitro cartilage generation. Trends Biotechnol 20: 351-356, 2002.

9. Levorson EJ, Hu O, Mountziaris PM, Kasper FK and Mikos AG: Cell-derived polymer/extracellular matrix composite scaffolds for cartilage regeneration, part 2: construct devitalization and determination of chondroinductive capacity. Tissue Eng Part C Methods 20: 358-372, 2014

10. Callahan LA, Ganios AM, McBurney DL, Dilisio MF, Weiner SD, Horton WE Jr and Becker ML: ECM production of primary human and bovine chondrocytes in hybrid PEG hydrogels containing type I collagen and hyaluronic acid. Biomacromolecules 13: 1625-1631, 2012.

11. Lin Z, Willers C, Xu J and Zheng MH: The chondrocyte: biology and clinical application. Tissue Eng 12: 1971-1984, 2006.

12. Caron MM, Emans PJ, Coolsen MM, Voss L, Surtel DA, Cremers A, van Rhijn LW and Welting TJ: Redifferentiation of dedifferentiated human articular chondrocytes: comparison of 2D and 3D cultures. Osteoarthritis Cartilage 20: $1170-1178,2012$.

13. Tekari A, Luginbuehl R, Hofstetter W and Egli RJ: Chondrocytes expressing intracellular collagen type II enter the cell cycle and co-express collagen type I in monolayer culture. J Orthop Res 32: 1503-1511, 2014.

14. Mhanna R, Öztürk E, Schlink P and Zenobi-Wong M: Probing the microenvironmental conditions for induction of superficial zone protein expression. Osteoarthritis Cartilage 21: 1924-1932, 2013. 
15. Luo T and Kiick KL: Collagen-like peptides and peptide-polymer conjugates in the design of assembled materials. Eur Polym J 49: 2998-3009, 2013.

16. Guo Y, Yuan T, Xiao Z, Tang P, Xiao Y, Fan Y and Zhang X: Hydrogels of collagen/chondroitin sulfate/hyaluronan interpenetrating polymer network for cartilage tissue engineering. $\mathrm{J}$ Mater Sci Mater Med 23: 2267-2279, 2012.

17. Lee CH, Singla A and Lee Y: Biomedical applications of collagen. Int J Pharm 221: 1-22, 2001

18. Goo HC, Hwang YS, Choi YR, Cho HN and Suh H: Development of collagenase-resistant collagen and its interaction with adult human dermal fibroblasts. Biomaterials 24: 5099-5113, 2003.

19. Kino-Oka M, Yashiki S, Ota Y, Mushiaki Y, Sugawara K, Yamamoto T, Takezawa T and Taya M: Subculture of chondrocytes on a collagen type I-coated substrate with suppressed cellular dedifferentiation. Tissue Eng 11: 597-608, 2005.

20. Gillogly SD and Wheeler KS: Autologous chondrocyte implantation with collagen membrane. Sports Med Arthrosc Rev 23 $118-124,2015$

21. Hindle P, Hall AC and Biant LC: Viability of chondrocytes seeded onto a collagen I/III membrane for matrix-induced autologous chondrocyte implantation. J Orthop Res 32: 1495-1502, 2014.

22. Zheng L, Fan HS, Sun J, Chen XN, Wang G, Zhang L, Fan YJ and Zhang XD: Chondrogenic differentiation of mesenchymal stem cells induced by collagen-based hydrogel: an in vivo study. J Biomed Mater Res A 93: 783-792, 2010.

23. Li YY, Cheng HW, Cheung KM, Chan D and Chan BP: Mesenchymal stem cell-collagen microspheres for articular cartilage repair: cell density and differentiation status. Acta Biomater 10: $1919-1929,2014$

24. Li W, Guo R, Lan Y, Zhang Y, Xue W and Zhang Y: Preparation and properties of cellulose nanocrystals reinforced collagen composite films. J Biomed Mater Res A 102: 1131-1139, 2014.

25. Zheng L, Jiang X, Chen X, Fan H and Zhang X: Evaluation of novel in situ synthesized nano-hydroxyapatite/collagen/alginate hydrogels for osteochondral tissue engineering. Biomed Mater 9: $065004,2014$.

26. Laydi F, Rahouadj R, Cauchois G, Stoltz JF and de Isla N: Hydroxyapatite incorporated into collagen gels for mesenchymal stem cell culture. Biomed Mater Eng 23: 311-315, 2013

27. Wang X, Grogan SP, Rieser F, Winkelmann V, Maquet V, Berge ML and Mainil-Varlet P: Tissue engineering of biphasic cartilage constructs using various biodegradable scaffolds: an in vitro study. Biomaterials 25: 3681-3688, 2004

28. Liang JZ: Reinforcement and quantitative description of inorganic particulate-filled polymer composites. Composites Part B Engineering 51: 224-232, 2013.

29. Fabbri P, Bondioli F, Messori M, Bartoli C, Dinucci D and Chiellini F: Porous scaffolds of polycaprolactone reinforced with in situ generated hydroxyapatite for bone tissue engineering. $\mathrm{J}$ Mater Sci Mater Med 21: 343-351, 2010.
30. Livak and Schmittgen: Analysis of relative gene expression data using real-time quantitative PCR and the $2-\Delta \Delta \mathrm{Ct}$ method. Methods 25: 402-408, 2001.

31. Yashiki S, Umegaki R, Kino-Oka M and Taya M: Evaluation of attachment and growth of anchorage-dependent cells on culture surfaces with type I collagen coating. J Biosci Bioeng 92: 385-388, 2001.

32. Nixon AJ, Rickey E, Butler TJ, Scimeca MS, Moran N and MatthewsGL: A chondrocyteinfiltrated collagentype I/IIImembrane (MACI ${ }^{\circledR}$ implant) improves cartilage healing in the equine patellofemoral joint model. Osteoarthritis Cartilage 23: 648-660, 2015.

33. Smeriglio P, Dhulipala L, Lai JH, Goodman SB, Dragoo JL, Smith RL, Maloney WJ, Yang F and Bhutani N: Collagen VI enhances cartilage tissue generation by stimulating chondrocyte proliferation. Tissue Eng Part A 21: 840-849, 2015.

34. Jia L, Duan Z, Fan D, Mi Y, Hui J and Chang L: Human-like collagen/nano-hydroxyapatite scaffolds for the culture of chondrocytes. Mater Sci Eng C 33: 727-734, 2013.

35. Hunter KT and Ma T: In vitro evaluation of hydroxyapatite-chitosan-gelatin composite membrane in guided tissue regeneration. J Biomed Mater Res A 101: 1016-1025, 2013

36. Chen J, Yu Q, Zhang G, Yang S, Wu J and Zhang Q: Preparation and biocompatibility of nanohybrid scaffolds by in situ homogeneous formation of nano hydroxyapatite from biopolymer polyelectrolyte complex for bone repair applications. Colloids Surf B Biointerfaces 93: 100-107, 2012.

37. Chen J,Zhang G, Yang S, Li J, Jia H, Fang Z and Zhang Q: Effects of in situ and physical mixing on mechanical and bioactive behaviors of nano hydroxyapatite-chitosan scaffolds. J Biomater Sci Polym Ed 22: 2097-2106, 2011.

38. Zhang CY, Lu H, Zhuang Z, Wang XP and Fang QF: Nano-hydroxyapatite/poly(L-lactic acid) composite synthesized by a modified in situ precipitation: preparation and properties. J Mater Sci Mater Med 21: 3077-3083, 2010.

39. Chen J, Nan K, Yin S, Wang Y, Wu T and Zhang Q: Characterization and biocompatibility of nanohybrid scaffold prepared via in situ crystallization of hydroxyapatite in chitosan matrix. Colloids Surf B Biointerfaces 81: 640-647, 2010.

40. Zhu W, Chen K, Lu W, Sun Q, Peng L, Fen W, Li H, Ou Y, Liu H, Wang D, et al: In vitro study of nano-HA/PLLA composite scaffold for rabbit BMSC differentiation under TGF- $\beta 1$ induction. In Vitro Cell Dev Biol Anim 50: 214-220, 2014.

This work is licensed under a Creative Commons Attribution-NonCommercial-NoDerivatives 4.0 International (CC BY-NC-ND 4.0) License. 